\title{
Rhetorical figures in German and Dutch print advertisements
}

Margot van Mulken/Lydia van Toorn (Nijmegen)

\section{Introduction}

In this paper, we focus on figurative speech (rhetorical figures) in advertising. Figures I and II are eloquent illustrations of the use of figurative speech. In Figure I, consumers are supposed to transfer their associations with royalty, femininity, loveliness, greatness and superiority to the alcoholic beverage in question. This means that the beer has been personified. In figure II, our connotations with pearls and nature are to be transferred to Krombacher beer. What happens is that the marketer relies on our knowledge and associations of queens and pearls to make a positive persuasive statement about the beverage he or she is hoping to sell. It is clear that the message is not straightforward: marketers refrain from stating directly that their beer is the best.

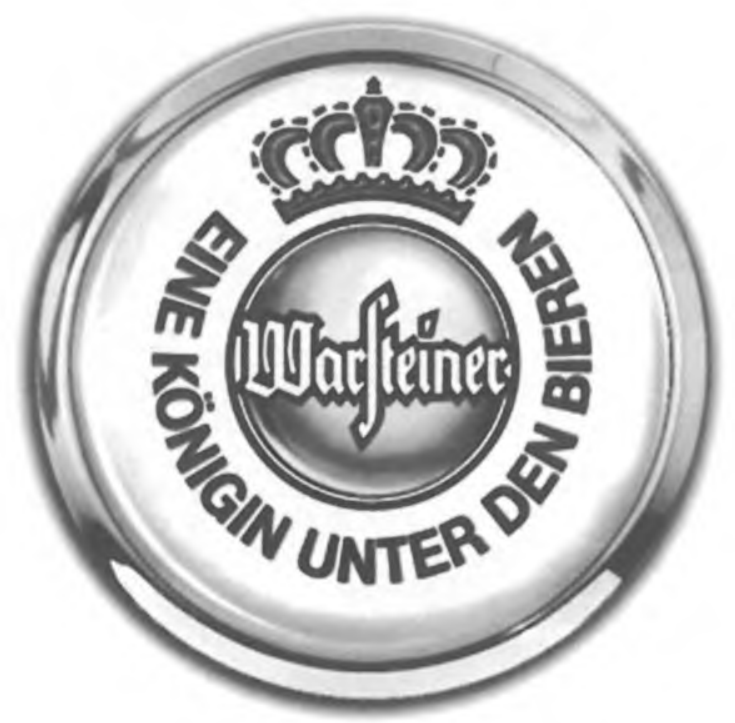

Figure 1: Warsteiner. Eine Königin unter den Bieren. (2004) 


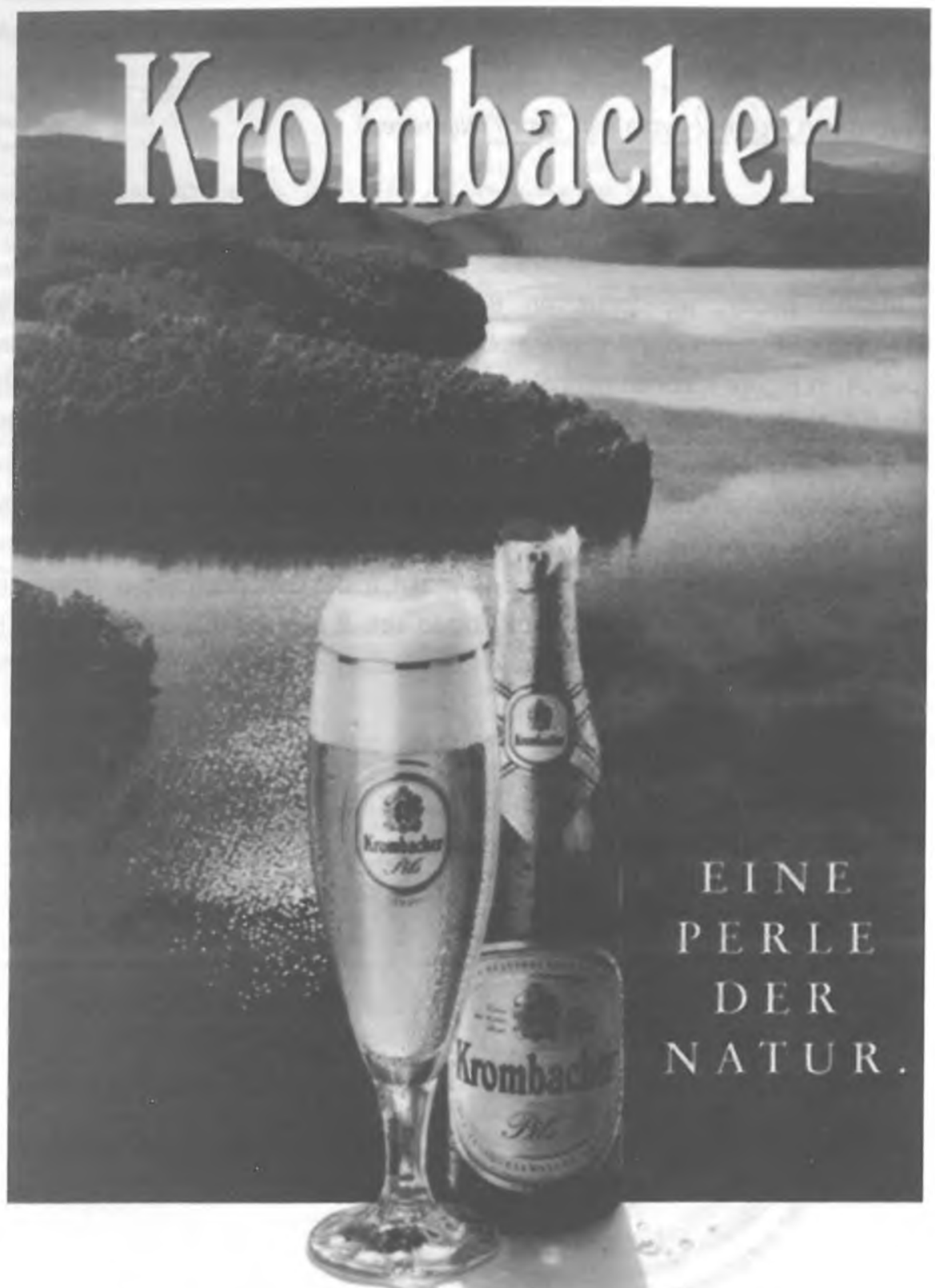

UIT FELSQUELLBASSER GEBRIUT.

Figure 2: Krombacher. Eine Perle der Natur (2004). 
This study reports on the validity and feasibility of the McQuarrie/ Mick framework, a classification of figurative speech in advertising. To this end, a hypothesis on intercultural differences in rhetorical preferences is tested.

Several scholars have already shown that figurative language works in both words and images. Tom/ Eves (1999: 13-27), Mothersbaugh/ Huhmann/ Franke (2002: 589-602) and Toncar/ Munch (2001: 55-65) report on research that underlines that advertisements that contain figurative speech are better retained, attract more attention, require more elaboration and are more appreciated than straightforward, normal advertisements. In order to understand how figurative speech works and to optimize the effectiveness of these advertisements, it is necessary to determine the effect of the various types of rhetorical figures. McQuarrie/ Mick (1996) have been the first to combine the classification of rhetorical figures and consumer response. They maintain that the ancient distinction between schemes and tropes remains relevant in modern advertising.

\section{Rhetorical figures in advertising}

McQuarrie/ Mick (1996) propose a rather transparent taxonomy (see Table 1).

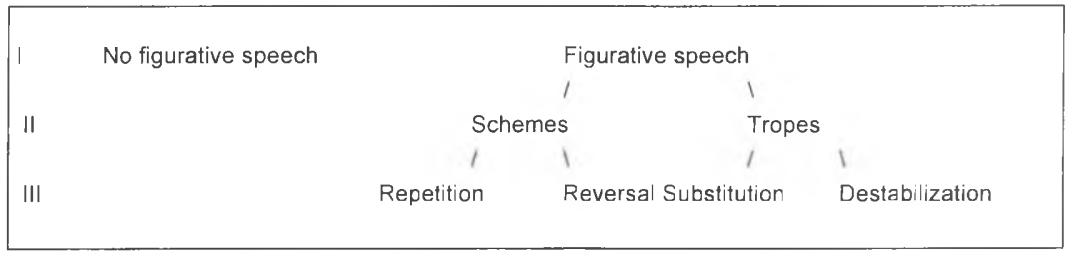

Table 1: McQuarrie/ Mick (1996: 426)

At the first level, it is decided whether an advertisement should contain figurative or non-figurative speech. All rhetorical figures are then divided into two subclasses (level II): the Quintilian distinction between schemes and tropes. Schemes are figures that concern the syntactical, superficial and sensory level of the message. They involve a deviation from the ordinary pattern or arrangement of words, for example excessive order or regularity. Repetition and alliteration are typical schematic figures, e.g. "Würzt scharf, ist scharf” (WMF Gewürzmühlen; Janich 1999). Tropes are figures that concern the semantic 
level of the message. The meaning of the message is transformed into a deviation from the ordinary whilst a principal signification of a word or image is involved. Excessive irregularity is often a sign of tropes. Metaphors and puns are examples of tropes, e.g. "Maggi. Jetzt in aller Munde" (Maggi). At the third level, McQuarrie/ Mick go on by subdividing the schemes into Repetition and Reversal. Reversal differs from Repetition by a higher grade of complexity. For instance, an antithesis is a figure of speech in which an element is not only repeated but also inverted, e.g. „So gross kann klein sein” (BMW), whereas alliteration, such as "Bäder brauchen Biff” (Biff) is an example of Repetition. Tropes are subdivided along the same lines of reasoning, where Substitution is a less complex type of trope than Destabilization. To resolve a case of Substitution such as an ellipsis, the receiver only has to correct part of the message (e.g. "Papier ist geduldig. Der Stern nicht"), whereas to resolve a case of Destabilization, the receiver has to infer the intended meaning on his or her own („Ikea - das unmögliche Möbelhaus”). "Tropes of substitution make a switch, while tropes of destabilization unsettle" (McQuarrie/ Mick 1996: 433).

Figures do not only occur in verbal communication and, therefore, Scott (1994) stresses the need for a theory of visual rhetoric. Kroeber-Riel (1993) also breaks a lance for interpretive analysis of imagery rhetoric: „Die Semiotik kann auch Auskunft über die tiefere Bedeutung von Bildern geben, die sich einer direkten empirischen Feststellung entzieht" (Kroeber-Riel 1993:31) ("The art of semiotics can teach us about the underlying meaning of images, something which can not be determined empirically", our translation). McQuarrie/ Mick (1999), too, insist upon the fact that the presence of rhetorical figures is not restricted to the words of an advertisement. They believe that their interpretive analysis can also be applied to visual rhetoric.

Figure 3 is an illustration of Repetition. We see how the shape of the mountain reflects the typical shape of the chocolate.

Figure 4 illustrates visual Substitution. The gentle touch of the female hand illustrates synaesthetically the taste of the alcoholic drink.

Figure 5 illustrates a case of Destabilization. The text reads "Gute Websites machen süchtig". The reader is supposed to understand that, in the same way as cocaine, illustrated in the form of the razor and the substance in the form of the first letter of the company name, can be addictive, the quality of websites 
produced by this company can be addictive. Once you have experienced them, you will never want something else.

\section{The cultural hypothesis}

Van Mulken (2003) has tried to establish the robustness of the McQuarrie/ Mick framework by testing it to a cultural hypothesis. The framework was applied to a large corpus of advertisements. On the basis of anthropological research on the differences in cultural values between the Dutch and the French, a distinct preference for rhetorical language was hypothesized for French advertisements as opposed to Dutch advertisements. One would expect that, if the McQuarrie/ Mick framework worked well, a generally accepted relative difference between two cultures, related to the style of communication, would have appeared. Since no significant differences between the French and Dutch preference for rhetorical speech in advertising were found, this was not the case.

It might be concluded that the McQuarrie/ Mick model should be discarded, but instead of making such a hasty conclusion, we decided to give the framework another go and applied it to another corpus. This time, we chose to verify whether the generally accepted difference between the Dutch and German population is reflected in a difference in their respective appreciation of figurative speech in advertising.

Figurative speech is a manner of expression in which the message is put in a non-straightforward way. In order to interpret the message, the receiver is obliged to decipher it by referring to previous knowledge. The sender relies heavily on the abilities of the receiver to decode the message, which means that the receiver is co-responsible for assigning a meaning to the message. He or she has to give some effort to interpret the communication. In essence, figurative speech is implicit. The context (previous knowledge, circumstantial knowledge) has to be used to infer the actual intended meaning of the message. The sender can therefore never be entirely sure that the receiver exactly interprets the message as it was intended. 


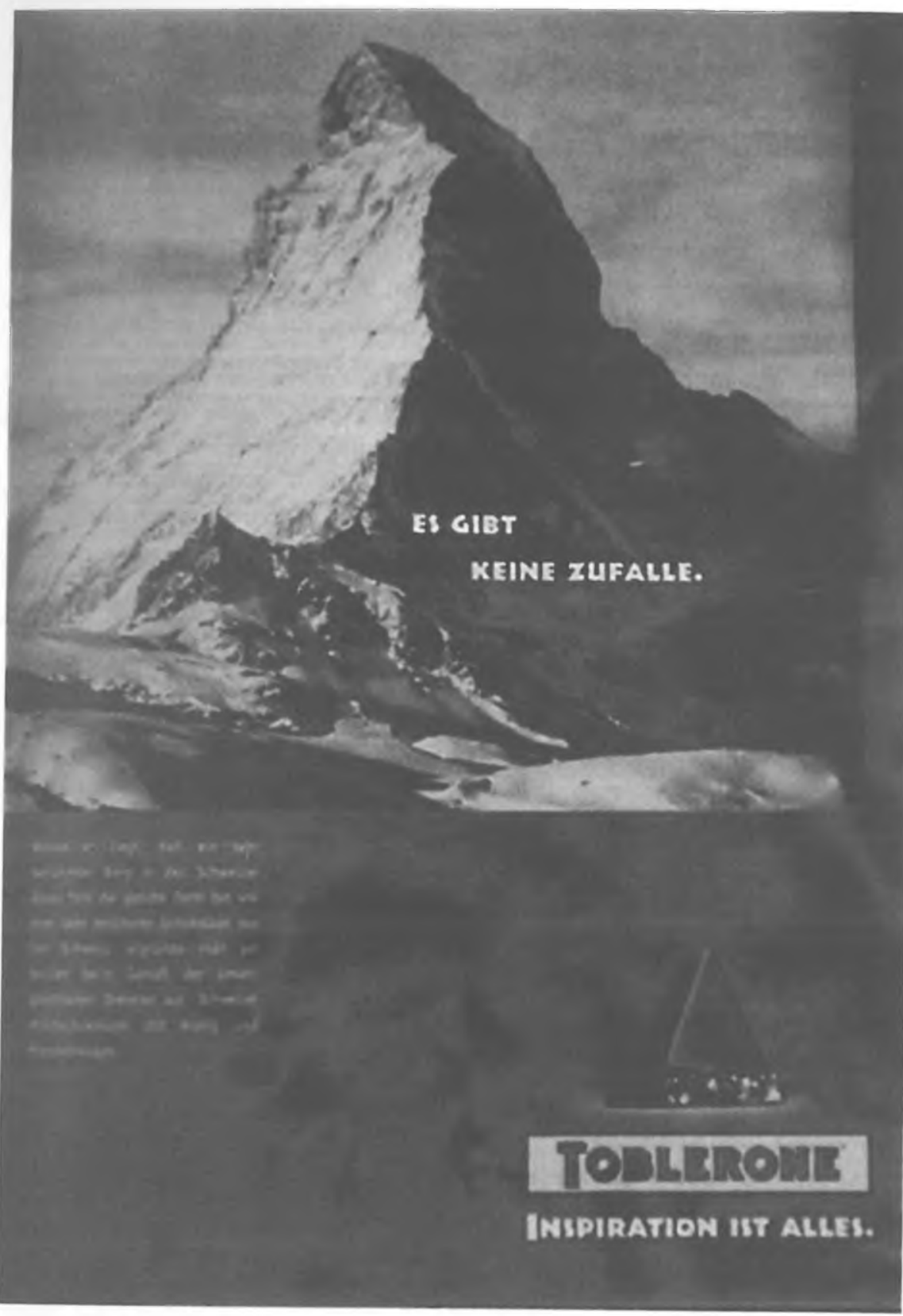

Figure 3: Repetition: Toblerone. Es gibt keine Zufälle. (2003) 


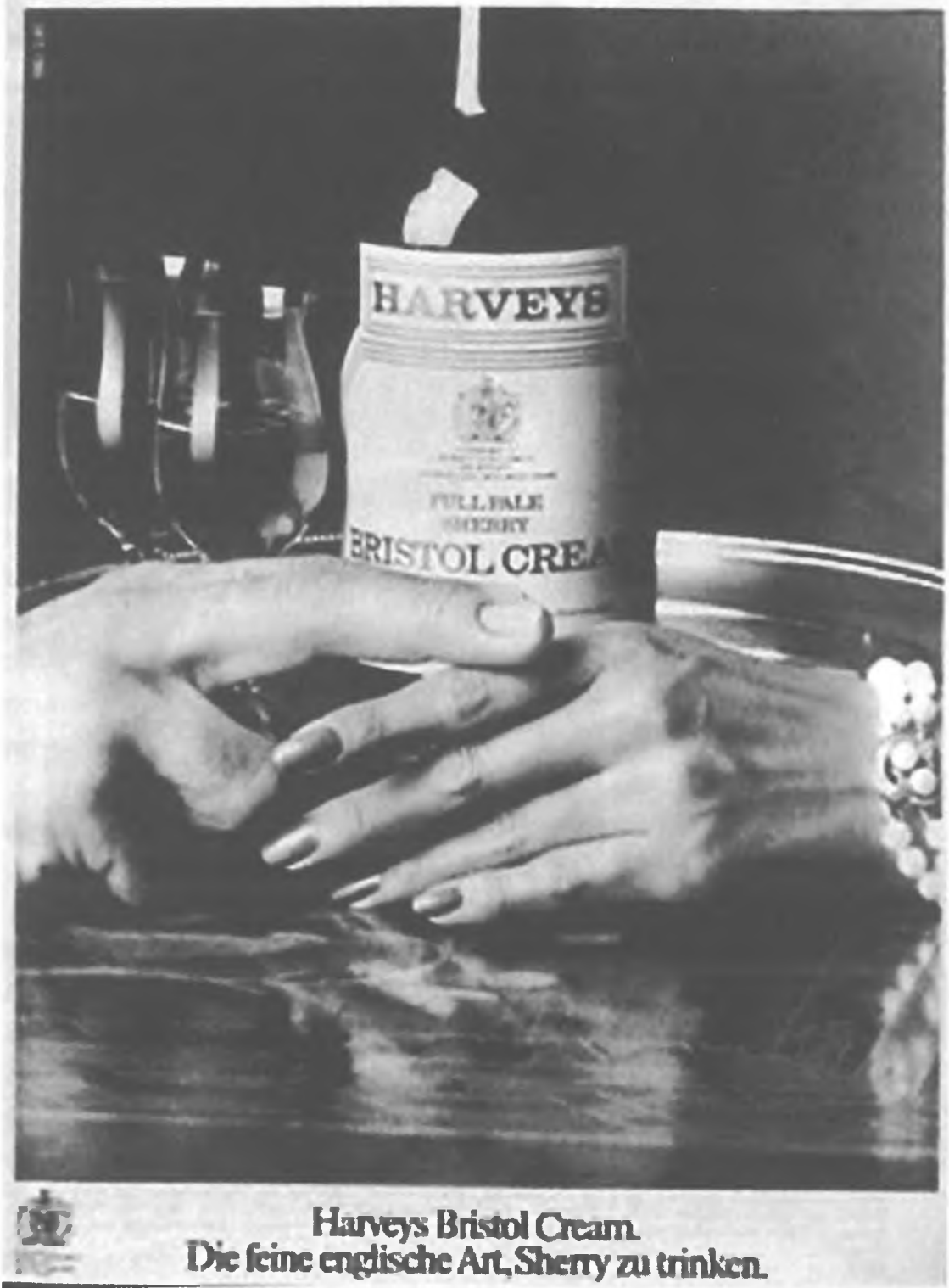

Figure 4: Substitution: Harveys Bristol Cream. Die feine englische Art, Sherry zu trinken (1975) 


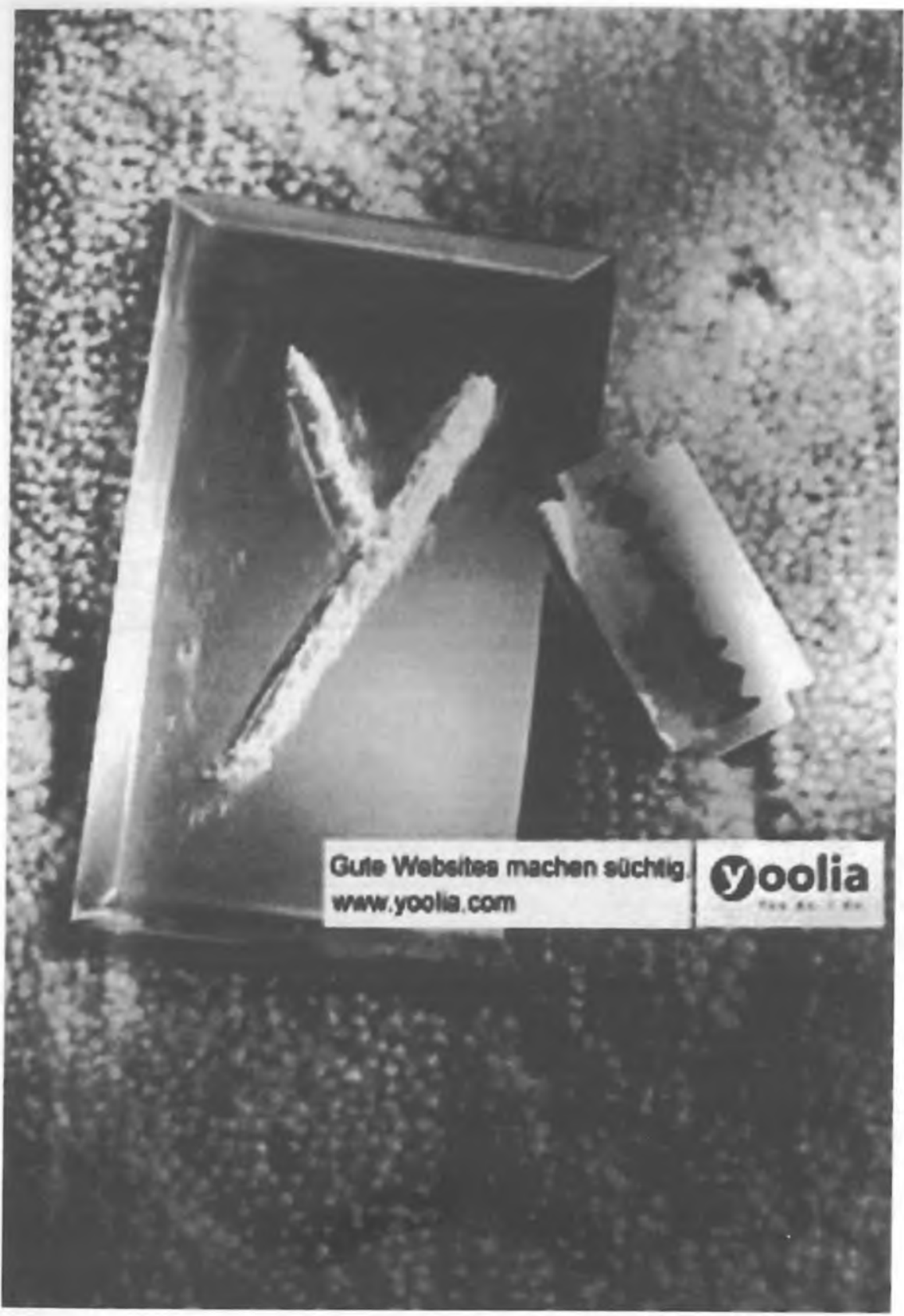

Figure 5: Destabilization: Yoolia. Gute Websites machen süchtig. (2000) 
Hofstede (2001) and De Mooij $(1998,2003)$ stress that German subjects have a greater inclination to avoid uncertainty than Dutch subjects. Germany scores 65 on the Hofstede uncertainty avoidance dimension, whilst the Netherlands score 53 on the same dimension. To cite De Mooij:

"The German advertising style is characterized by the need for structure and explicit language to avoid ambiguity. Strong uncertainty avoidance, which makes management want to avoid ambiguity, is one of the explanations for the fact that German advertising uses so little humor as compared with British advertising. German advertisements show a strong information orientation; they are direct and factual. [...] Germans downplay imagination and favor orderly, logical presentations. Their style is clean, rational, straightforward, and serious." (De Mooij 1998: 274-5)

It is therefore to be expected that German advertisers have a greater reluctance to use figurative speech in their messages than Dutch advertisers, since the Germans prefer to be sure that the message is understood in the way they intended it. The use of non-figurative speech is then the safest way to make sure that receivers completely understand the advertisement. One would expect that, in spite of the reported advantages of figurative speech, German advertisers use less figurative speech in their advertisements than their Dutch counterparts do. Therefore, the hypothesis of this study is that Dutch advertisers use more (complex) figurative speech than German advertisers do.

\section{Method}

We applied the McQuarrie/ Mick framework to a large corpus of print advertisements in German and Dutch magazines. A sample of 502 advertisements was compiled, 249 of which were German advertisements and 253 of which were Dutch advertisements. The first 20 full-page advertisements of every month in the opinion weeklies Der Spiegel (German) and Elsevier (Dutch) of the year 2000 were used. Two independent judges, both Dutch raters who had studied German and were trained in the technique, categorized $25 \%$ of the data. It was verified whether the German inclination to avoid uncertainty in communication became apparent with regard to the use of rhetorical speech.

What strikes first is that the reliability check we performed on 25 percent of the sample was rather poor. In spite of careful instruction of both raters, their comparable background and familiarity with rhetorical speech, interrater 
agreement was rather disappointing, i.e. $\mathrm{k}<.4$, (= fair). This is a relatively common phenomenon in interpretive analyses, but it remains something to worry about.

\section{Results}

The results of the analysis on the two samples are presented in Table 2.

\begin{tabular}{llrr}
\hline \multirow{2}{*}{ no rhetoric } & Dutch & German \\
Verbal & repetition & 94 & 91 \\
& reversal & 17 & 24 \\
& substitution & 33 & 19 \\
& destabilization & 52 & 31 \\
Visual & repetition & 6 & 66 \\
& reversal & 13 & 5 \\
& substitution & 10 & 8 \\
& destabilization & 60 & 52 \\
Total & & 305 & 306 \\
\hline
\end{tabular}

Table 2: Rhetorical Figures in Dutch Elsevier $(\mathrm{N}=253)$ and German Der Spiegel $(\mathrm{N}=249)$, based on the taxonomy of McQuarrie/ Mick (1999). Advertisements may contain both visual and verbal rhetorical figures, therefore the total number is more than $\mathrm{N}$.

We see that 30 percent of our two samples contains no rhetorical figures. The German sample contains slightly more verbal Destabilization figures than the Dutch sample, but this is compensated for in the visual distribution, where the Dutch sample contains more Destabilization figures. However, a chi-square test reveals that there are no significant differences between the German or Dutch sample $(p>.05)$. Table 3 regroups the two modes of expression and totalizes the four types of rhetorical figures.

\begin{tabular}{llll}
\hline & Netherlands & Germany & Total \\
\hline No Figure & $30.82 \%$ & $29.74 \%$ & $30.28 \%$ \\
Repetition & $7.54 \%$ & $9.48 \%$ & $8.51 \%$ \\
Reversal & $10.82 \%$ & $9.48 \%$ & $10.15 \%$ \\
Substitution & $14.10 \%$ & $12.75 \%$ & $13.42 \%$ \\
Destabilization & $36.72 \%$ & $38.56 \%$ & $37.64 \%$ \\
\hline
\end{tabular}

Table 3: Rhetorical Figures in Dutch ( $\mathrm{N}=253)$ Elsevier and German $(\mathrm{N}=249)$ Der Spiegel, based on the taxonomy of McQuarrie/ Mick (1999) 


\section{Conclusion/ Discussion}

Our hypothesis that Dutch advertisements contain more figurative speech than German advertisements has to be refuted. We see that the distribution of figures over the five classes is similar in both countries. We also see that the German and Dutch advertisements contain many instances of Destabilization. The corpus contained more advertisements that used Destabilization than advertisements that did not use figurative speech at all.

We may conclude that the German inclination towards avoidance of uncertainty is not applicable to print advertising. However, since there did not appear any differences between the French and Dutch advertising preference for rhetoric (Van Mulken 2003), we prefer to look for an alternative explanation. It becomes apparent that cultural differences in the use of figurative speech cannot be found using the McQuarrie/ Mick framework.

In view of the enormous quantity of Destabilization figures in both samples, we deem the framework to be too coarse-grained. Too many items are captured into one taxon, whereas it can be shown that there is a difference in complexity between a metaphor such as we have seen in Figure 1 and the verbo-pictorial rhetorical figure in Figure 6.

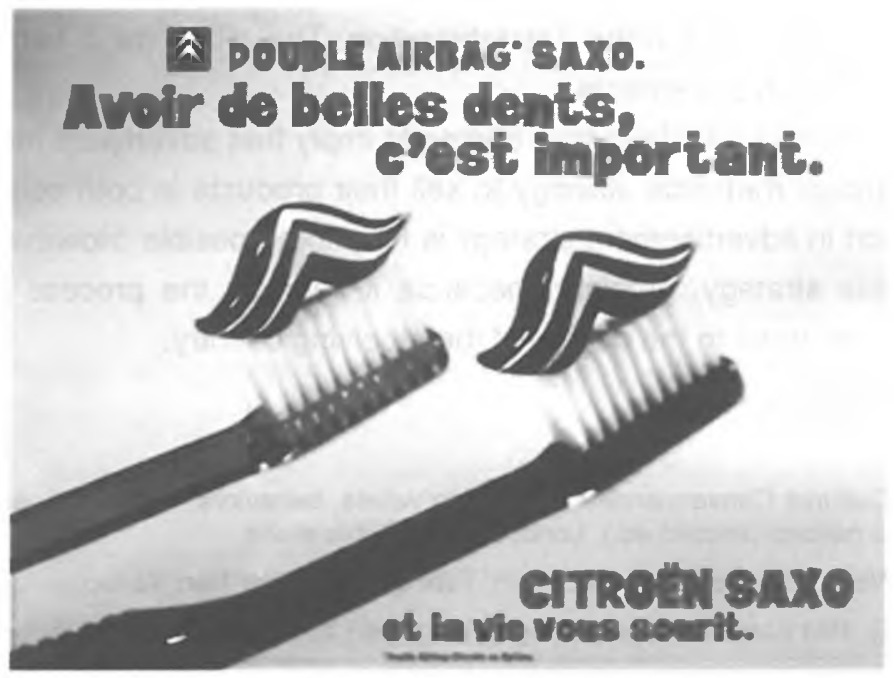

Figure 6: Citroën Saxo. Avoir de belles dents, c'est important. Citroën Saxo et la vie vous sourit. (It is important to have beautiful teeth - Citroën Saxo and life laughs at you) (2004) 
A lot of information is presupposed in this advertisement. The reader is supposed to be familiar with the sender, the car manufacturer Citroën, because cars are not mentioned in the advertisement. Second, the reader is supposed to be familiar with the beneficial effects of airbags (they preserve life and, by inclusion, teeth). If he or she is familiar with the Citroën logo, he or she will notice that the toothpaste is similar to that logo. In other words, the Citroën Saxo is as important for teeth as toothpaste. We also infer that the statement "It is important to have nice teeth" is humorously intended. The marketer hopes that the receiver understands and appreciates the pun of the advertisement. Notice how the pay-off "Life laughs at you" concords with this line of reasoning. We see then that the number of inferential steps in Figure 6 is considerably higher than that in Figure 1 (implicit word-image relation and implicit messagesender relation). The complexity of this type of figurative speech is therefore higher, although both instances will be counted as Destabilization figures in the McQuarrie/ Mick framework. In order to do justice to one of the claims of this framework (to account for the different degrees of complexity), a refinement of the Destabilization class is therefore necessary (see also Phillips/McQuarrie 2004). We believe that the presence or absence of interaction between word and image should be integrated in the framework (see Van Mulken/ Boon/ Kleijer 2005) as a special class within Destabilization. This will allow a better proliferation of complex advertisements.

The absence of intercultural differences seems to imply that advertisers may use a relatively complex rhetorical strategy to sell their products in both countries. Standardization in advertisement strategy is therefore possible. However, the execution of this strategy, precisely because it involves the process of implication, must be adapted to the culture of the receiving country.

\section{References}

Hofstede, G. (2001): Cultures Consequences, comparing values, behaviors, institutions, and organizations across nations (second ed.). London: Sage Publications.

Janich, Nina (1999): Werbesprache. Ein Arbeitsbuch. Tübingen: Gunther Narr Verlag.

Kröber-Riel, W. (1993): Bild Kommunikation, Imagerystrategien für die Werbung. München: Vahlen Verlag.

McQuarrie, E./ Mick, D. G. (1996): Figures of Rhetoric in Advertising Language. Journal of Consumer Research, 22 (4), 424-437. 
McQuarrie, E./ Mick, D. G. (1999): Visual Rhetoric in Advertising: Text-Interpretive, Experimental and Reader-Response Analyses. Journal of Consumer Research, 26 (1), 37 53.

McQuarrie, E./ Mick, D. G. (2003): The Contribution of Semiotic and Rhetorical Perspectives to the Explanation of Visual Persuasion in Advertising. In L. Scott, M./ R. Batra (Eds.), Persuasive Imagery, A Consumer Response Perspective. London: Lawrence Erlbaum Associates, 191-221.

Mooij, M. de (1998): Global Marketing and Advertising, Understanding Cultural Paradoxes. Thousand Oaks London New Delhi: Sage.

Mooij, M. de (2003): Consumer Behavior and Culture, consequences for Global Marketing and Advertising. Thousand Oaks, London, New Delhi: Sage.

Mothersbaugh, D. L./ Huhmann, B. A./ Franke, G. R. (2002): Combinatory and Separative Effects of Rhetorical Figures on Consumers Effort and Focus in Ad Processing. Journal of Consumer Research, 28 (4), 589-602.

Mulken, M. van (2003): Analyzing rhetorical devices in print advertisements. Document Design, 4 (2), 115-128.

Mulken, M. van/ Boon, N./ Kleijer, S. (2005): Verbal Anchoring and Implict Meaning in Magazine Advertisements. In C. Ilie (Ed.), Language, culture, rhetoric: Cultural and rhetorical perspectives on communication, ASLA. Vol. 17. Örebro: ASLA, 143-153.

Phillips, B./ McQuarrie, E. (2004): Beyond Visual Metaphor: A New Typology of Visual Rhetoric in Advertising. Marketing Theory, 4 (1/2), 111-134.

Scott, L. M. (1994): Images in Advertising: the Need for a Theory of Visual Rhetoric. Journal of Consumer Research, 21 (3), 252-273.

Tom, G./ Eves, A. (1999): The use of rhetorical devices in advertising. Journal of Advertising Research, 25 (3), 13-27.

Toncar, M./ Munch, J. (2001): Consumer Responses to Tropes in Print Advertising. Journal of Advertising, 30 (1), 55-65. 